\title{
Improved HPLC method for the analysis of chlorophylls and carotenoids from marine phytoplankton
}

\author{
S. W. Wright ${ }^{1}$, S. W. Jeffrey ${ }^{2}$, R. F. C. Mantoura ${ }^{3}$, C. A. Llewellyn ${ }^{3}$, T. Bjørnland ${ }^{4}$, \\ D. Repeta ${ }^{5}$, N. Welschmeyer ${ }^{6}$ \\ ${ }^{1}$ Australian Antarctic Division, Channel Highway, Kingston, Tasmania 7050, Australia \\ ${ }^{2}$ CSIRO Division of Fisheries, GPO Box 1538, Hobart, Tasmania 7001, Australia \\ ${ }^{3}$ Plymouth Marine Laboratory, Prospect Place, West Hoe, Plymouth, PL1 3DH, United Kingdom \\ ${ }^{4}$ Organic Chemistry Laboratories, University of Trondheim-NTH, N-7034, Trondheim, Norway \\ ${ }^{5}$ Department of Chemistry, Woods Hole Oceanographic Institution, Woods Hole, Massachusetts 02643, USA \\ ${ }^{6}$ Moss Landing Marine Laboratory, PO Box 450, Moss Landing, California 95039, USA; and Monterey Bay Aquarium Research \\ Institute, Pacific Grove, California 94960, USA
}

\begin{abstract}
Using a ternary gradient system, over 50 carotenoids, chlorophylls and their derivatives were separated from marine phytoplankton. Only 2 pairs of carotenoid pigments $\left(19^{\prime}\right.$-butanoyloxyfucoxanthin and siphonaxanthin, and 19'-hexanoyloxyfucoxanthin and $9^{\prime}$-cis-neoxanthin) and 3 chlorophylls (chlorophylls $c_{1}, c_{2}$ and $\mathrm{Mg} 2,4$ divinyl pheoporphyrin $a_{5}$ monomethyl ester [Mg2,4D]) were not resolved. Pigment chromatograms are presented for 12 uniaigal cultures from 10 algal classes important in the marine envronment: Amphidinium carterae Hulbert (Dinophyceae); Chroomonas salina (Wislouch) Butcher (Cryptophyceae); Dunaliella tertiolecta Butcher (Chlorophyceae); Emiliania huxleyi (Lohmann) Hay et Mohler and Pavlova lutheri (Droop) Green (Prymnesiophyceae); Euglena gracilis Klebs (Euglenophyceae); Micromonas pusilla (Butcher) Manton et Parke and Pycnococcus provasolii Guillard (Prasinophyceae); Pelagococcus subvinidis Norris (Chrysophyceae); Phaeodactylum tricornutum Bohlin (Bacillariophyceae); Porphyridium cruentum (Bory) Drew et Ross (Rhodophyceae), and Synechococcus sp. (Cyanophyceae). A chromatogram is also given of a complex mixture of over 50 algal pigments such as might be found in a phytoplankton field sample. This method is useful for analysis of phytoplankton pigments in seawater samples and other instances where separations of complex pigment mixtures are required
\end{abstract}

\section{INTRODUCTION}

A number of methods for the determination of phytoplankton pigments are available which have various levels of sophistication and accuracy. These range from widely used simple spectrophotometric and fluorometric methods for chlorophylls $a, b$ and $c$ and their Mg-free derivatives (Holm-Hansen et al. 1965, Lorenzen 1967, Strickland \& Parsons 1972, Jeffrey \& Humphrey 1975, Lorenzen \& Jeffrey 1980) to chromatographic methods which include thin-layer chromatography (Jeffrey 1981), high performance thin-layer chromatography (HPTLC; Wright \& Jeffrey 1987) and high performance liquid chromatography (HPLC; reviewed by Roy 1987). The chromatographic methods separate an array of chlorophylls and carotenoids, which act as indicators of microscopic plant biomass, and biological markers for algal types, recycling processes and productivity measurements (Jeffrey 1974, Hooks et al. 1988, Bjornland \& Liaaen-Jensen 1989, Strom \& Welschmeyer 1991).

Although a number of HPLC methods for phytoplankton pigments have been published over the past few years, no one method is ideal for all pigments. Techniques for the separation of chlorophylls and their derivatives include those of Mantoura \& Llewellyn (1983), Bidigare et al. (1985), Gieskes \& Kraay (1986a), and Zapata et al. (1987), while the best methods for carotenoid resolution are those of Wright \& Shearer (1984) and Repeta \& Gagosian (1982). The last method has the disadvantages of using a silica column which causes degradation of chlorophylls, while the Wright \& Shearer method does not resolve the polar chlorophylls $c_{1}, c_{2}, c_{3}$ and $\mathrm{Mg}-2,4$ divinyl phaeoporphyrin $a_{5}$ mono- 
methyl ester (Mg2,4D) which coelute as a single peak, or adequately resolve the chlorophyllides $a$ and $b$. A single method, suitable for the full range of important chlorophylls, chlorophyll derivatives and taxonomically significant carotenoids found in phytoplankton was urgently needed, particularly for international oceanographic programs currently underway for climate change studies (e.g. the Joint Global Ocean Flux Study).

Aware of the need to evaluate and compare pigment methods, the Scientific Committee for Oceanic Research (SCOR) founded 'Working Group 78: Measurement of Photosynthetic Pigments in Seawater', whose objectives included: (1) comparing spectrophotometric, fluorometric and HPLC methods for chlorophyll a determination; (2) recommending a simple isocratic HPLC shipboard technique for chlorophylls and derivatives; (3) evaluating gradient HPLC techniques for detailed separations of chlorophylls and carotenoids.

For the third objective, the Working Group members who attended the SCOR Chlorophyll Workshop at the CSIRO Marine Laboratories, November, 1988 used the method of Wright \& Shearer (1984) for carotenoids and non-polar chlorophylls, and added to it an initial solvent system used by Welschmeyer \& Hoepffner (in press) for separating polar chlorophylls An improved method resulted which separates more than 50 chlorophylis, carotenoids, their derivatives and isomers from marine phytoplankton in one ternary gradient system. This paper gives details of the HPLC method and examples of chromatograms from reference algae. Quantitative analyses form part of the SCOR Workshop Report, and are not duplicated here. While several carotenoids and 3 chlorophyll c pigments (Jeffrey 1989) are not resolved, this new method provides oceanographers with a significantly improved system for the analysis of phytoplankton pigments in the sea.

\section{MATERIALS AND METHODS}

Algal cultures. Because of the instability and commercial non-availability of pure algal pigment standards, the SCOR Working Group 78 recommended that the source of such standards should be reference algal cultures whose pigments had been fully characterised A small number of species were selected (Table 1) which together contained most significant pigments known to be found in marine phytoplankton (Table 2). Additional cultures to those recommended by SCOR were included for the present work to ensure that a full range of algal classes was represented.

The cultures were maintained in the CSIRO Algal Culture Collection (Jeffrey 1980). Table 1 lists clonal designation, CSIRO Culture Code number, culture medium, temperature and light intensities used for growth as well as references to the chemical identification of pigments. All cultures were grown in stationary $125 \mathrm{ml}$ Erlenmeyer flasks containing $75 \mathrm{ml}$ culture medium. Illumination was provided by banks of Philips 'daylight' fluorescent tubes, beneath glass shelves supporting the culture flasks. Light irradiances $12: 12 \mathrm{~h}$ light: dark cycles) were measured in the culture medium with a Biospherical Optics light meter. Culture stocks were transferred every 7 to $10 \mathrm{~d}$.

Culture harvest. Cells were harvested before the end of $\log$ phase and $10 \mathrm{ml}$ culture aliquots were taken for pigment analysis. These were filtered through $25 \mathrm{~mm}$ Whatman GF/F filters under low vacuum (e.g. $\leq 100 \mathrm{~mm} \mathrm{Hg}$ ) and rinsed with filtered medium or seawater. The filter was extracted immediately, or was folded, placed in a labelled cryotube and immediately frozen in liquid nitrogen. Several replicates of each culture were made. The time taken from filtration to liquid nitrogen was not more than $30 \mathrm{~s}$, and for the experiments described in this paper, storage in liquid nitrogen was not more than 1 to $10 \mathrm{~d}$.

Field samples. The sample illustrated was collected from $90 \mathrm{~m}$ depth at $51^{\circ} 54^{\prime} \mathrm{S}, 73^{\circ} 14^{\prime} \mathrm{E}$ in the Southern Ocean in the vicinity of Heard Island on 9 June 1990. Seawater (1 to 5 l) was filtered through a $25 \mathrm{~mm}$ diameter Whatman GF/F filter. This was folded, blotted dry and stored in a cryotube under liquid nitrogen and returned to the laboratory for HPLC. The particular sample illustrated was stored for 3 mo before analysis. No discernible changes occur during this time (SCOR Working Group 78, unpubl.).

Pigment extraction: cultures. The SCOR Working Group 78 report will separately consider in detail the optimum methods for extraction of pigments from cultures and field samples. The frozen filter containing the algal sample was cut into small slices (several mm $\times 1 \mathrm{~cm})$ and was ground for $30 \mathrm{~s}$ in a motorized grinder with a teflon pestle in $2.7 \mathrm{ml} 100 \%$ acetone. Water $(0.3 \mathrm{ml})$ was then added to make up to $90 \%$ acetone, and the sample reground. Methanol could have been used as extraction solvent, and often is for field samples (see below). The results of comprehensive tests of solvents and extraction protocols will be described in the SCOR report. The filter plus acetone extract was transferred to a plastic centrifuge tube cut down to $5 \mathrm{ml}$, which had been 'needle-pierced' at the bottom (Wright \& Shearer 1984) and covered with a $5 \mathrm{~mm}$ circle of GF/ $F$ filter. The cut-down centrifuge tube containing the extract was then placed in the top of a $10 \mathrm{ml}$ conical glass centrifuge tube, and both tubes centrifuged in tandem for $3 \mathrm{~min}$ at $700 \times \mathrm{g}$. The clear green-yellow extract was collected in the lower glass centrifuge tube, while the filter debris remained in the upper tube. The 


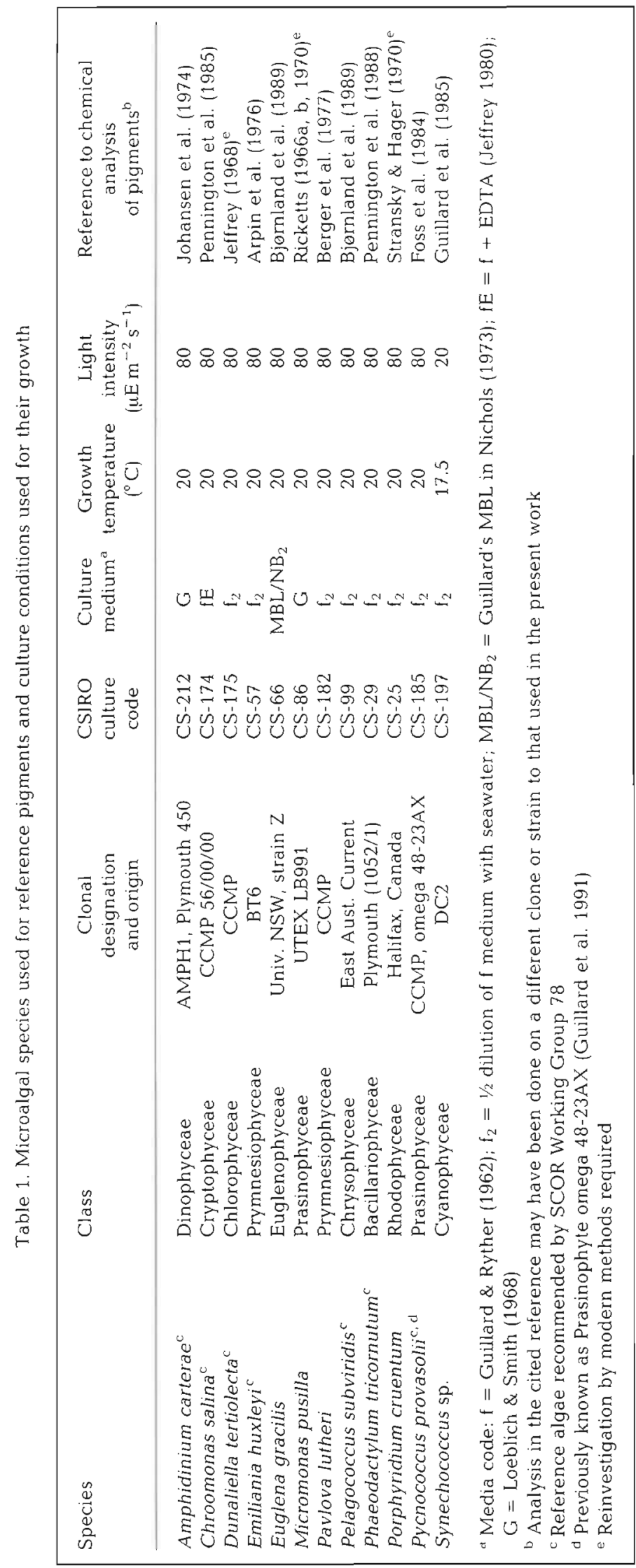




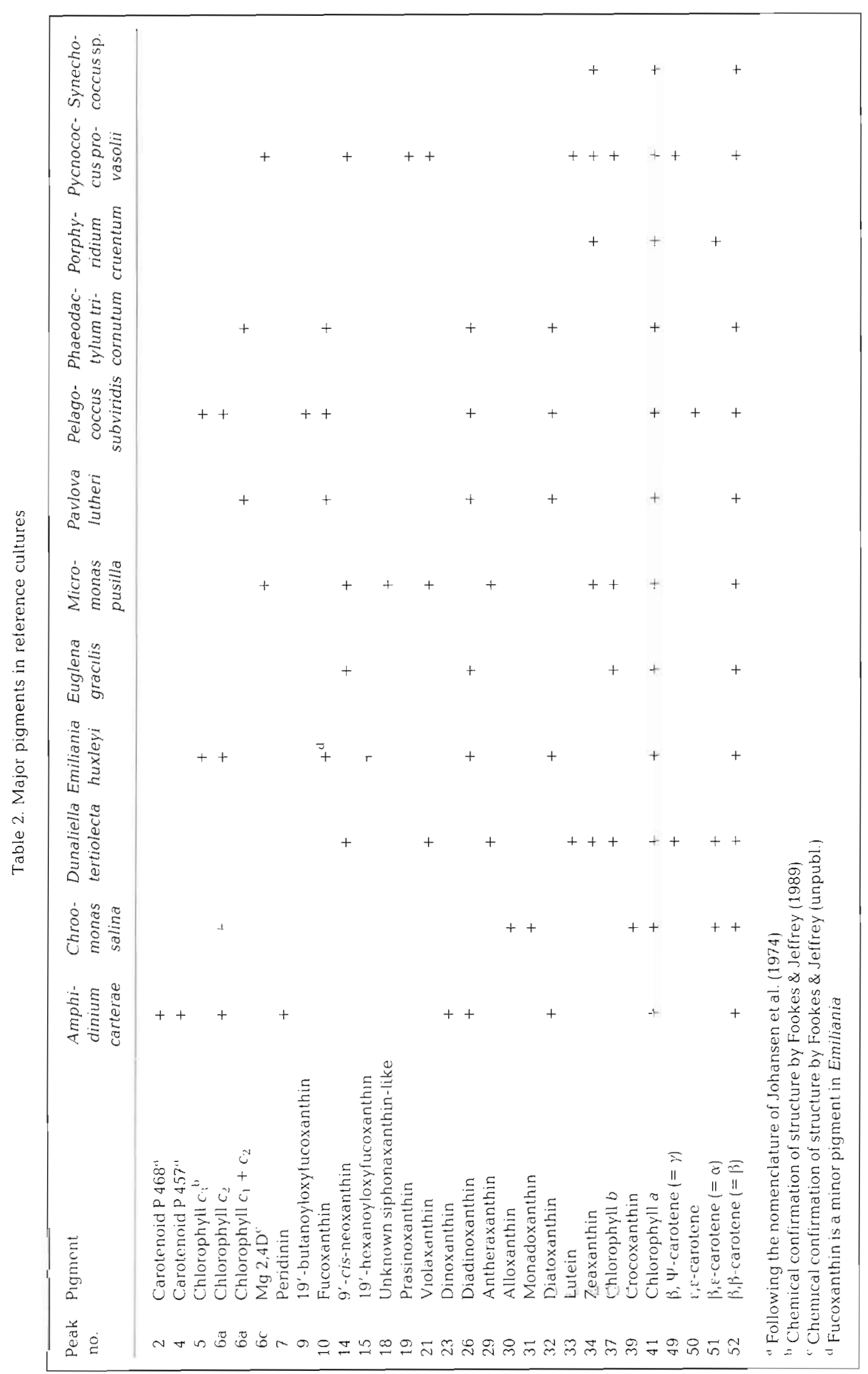


homogenizer and pestle were rinsed with $1 \mathrm{ml} 90 \%$ acetone, which was added to the filter debris in the upper tube, and recentrifuged. The clear combined extracts from the lower tube were then transferred to a $5 \mathrm{ml}$ volumetric flask and made up exactly to $5 \mathrm{ml}$ with $90 \%$ acetone to ensure volumetric accuracy. After filtering through a Millex-SR $0.5 \mu \mathrm{m}$ filter (Millipore), an aliquot of the extract (about $25 \mu \mathrm{l}$ ) was injected immediately into the liquid chromatograph for pigment analysis.

Pigment extraction: field samples. The procedure for field samples was slightly different from that of the cultured samples because of the need to keep extraction volumes to a minimum and hence achieve a higher final concentration of pigments. Filters were cut into small pieces (several $\mathrm{mm} \times 1 \mathrm{~cm}$ ) and sonicated for $30 \mathrm{~s}$ in the cut down centrifuge tubes using $1.5 \mathrm{ml}$ methanol (or acetone) and a Braun Labsonic 1510 equipped with a 4 $\mathrm{mm}$ diameter probe, operated at $50 \mathrm{~W}$. The bottom needle-hole in the centrifuge tube was securely covered with a single layer of Nescofilm or Parafilm to prevent solvent leakage during sonication. During centrifugation (as above), the film burst allowing the extract to collect in the lower tube. The extract was filtered (Millex-SR $0.5 \mu \mathrm{m}$ ) and then, immediately before injection, was diluted with water to $80 \% \mathrm{MeOH}$ (or $66 \%$ acetone if acetone was used). $125 \mu \mathrm{l}$ of the diluted extract was injected. In general, the field samples were much less concentrated than the calture samples, hence a larger injection volume was required. However, if a large aliquot of strong solvent (e.g. methanol or $90 \%$ acetone) was injected, then the pigment bands, particularly the early ones, were too broad and retention times decreased. Dilution of the extract, as mentioned above, increased the affinity of pigments for the column during the loading step, resulting in sharper peaks and allowing greater overall loading than possible with the undiluted extract. It is important that the extract is not diluted until immediately before injection, since highly aqueous extracts are not stable and pigment losses (adsorption and precipitation, particularly the more hydrophobic pigments) occur on standing.

It was suggested by an anonymous reviewer that the addition of $2 \%$ ammonium acetate buffer to the methanol extraction solvent improved the height and sharpness of the chlorophyll $c$ peaks. This has been confirmed in our laboratories.

High performance liquid chromatography. Three HPLC instruments were used for comparison of separation efficiencies: (1) a Waters Associates liquid chromatograph comprising M6000A, M45 and M501 pumps, Valco injector, Hewlett-Packard 8450A diode array spectrophotometer, and a Waters 440 absorbance detector, connected via a Waters System Interface Module to a microcomputer running Waters Maxima
Software; (2) a Varian Model 5000 liquid chromatograph with Varian UV50 variable wavelength detector, Varian Fluorichrome fluorescence detector, and Varian 'Vista' 402 data module; and (3) a Spectraphysics HPLC comprising an SP8800 ternary pump. SpectraFocus detector and a Gilson 231 autosampler (200 ul loop) with samples refrigerated to $-10^{\circ} \mathrm{C}$. Chromatograms from the Varian 5000 were used in Figs. 1 \& 2, and from the Spectraphysics instrument in Fig. 3. Reversed phase columns used were Spherisorb ODS2, $25 \mathrm{~cm} \times 4.6 \mathrm{~mm}$ ID, $5 \mu \mathrm{m}$ particle size, packed by Australian Government Analytical Laboratories, Melbourne $\left(90000\right.$ to 100000 plates $\left.\mathrm{m}^{-1}\right)$. Similar resolution was obtained with commercial columns such as Waters Resolve $C_{18}$ and Activon Ultratechsphere, although some $\mathrm{C}_{18}$ columns tested were not as efficient, particularly in the ability to resolve lutein and zeaxanthin.

Pigment detection was at $436 \mathrm{~nm}$ (Figs. 1 to 3) for all chlorophylls and carotenoids and $405 \mathrm{~nm}$ for phaeophytin $a$ and phaeophorbide $a$ (not shown). The solvent systems used were as follows:

$$
\begin{aligned}
& \text { Solvent A: 80:20 methanol : } 0.5 \mathrm{M} \text { ammonium } \\
& \text { acetate (aq.: } \mathrm{pH} 7.2 \mathrm{v} / \mathrm{v} \text { ) } \\
& \text { Solvent B: } 90: 10 \text { acetonitrile }(210 \mathrm{~nm} \text { UV cut-off } \\
& \text { grade) : water ( } v / v) \\
& \text { Solvent C: ethyl acetate (HPLC grade) }
\end{aligned}
$$

Flow rate was $1 \mathrm{ml} \mathrm{min}{ }^{-1}$. The gradient systems used are shown in Table 3 . In the analytical system an initial 4 min gradient from $100 \%$ A to $100 \%$ B provided improved separation of polar compounds. The program returned to initial conditions and re-equilibrated for $5 \mathrm{~min}$ before the next sample injection. Table $3 \mathrm{a}$ shows the gradient used on the Varian system to abtain the results presented in Figs. $1 \& 2$. Table $3 b$ shows the modified procedure for the Spectraphysics system. In this case, the slope of the gradient for Solvent $C$ was reduced between 2.6 and $13.6 \mathrm{~min}$ for the region of the chromatogram between fucoxanthin and chlorophyll $a$ (increasing the resolution in the most complex region of the chromatogram) and increased elsewhere to reduce the overall time for analysis. Table $3 \mathrm{c}$ shows the shutdown protocol whereby the column is washed in the strongest solvent (ethyl acetate) to remove any retained material before being shutdown overnight or for storage. The start-up protocol is the reverse of this program.

Methanol, acetonitrile and ethyl acetate were HPLC grade reagents from Waters and BDH (Hypersolve), used without further purification other than filtration and degassing by sonication. Water was purified using a Millipore Milli-Q system. Ammonium acetate was A.R. grade. 
Table 3. HPLC solvent system programs

\begin{tabular}{|c|c|c|c|c|c|}
\hline $\begin{array}{l}\text { Time } \\
\text { (min) }\end{array}$ & $\begin{array}{c}\text { Flow } \\
\text { rate } \\
\text { mi min }^{-1}\end{array}$ & $\%$ A & $\% B$ & $\% \mathrm{C}$ & Conditions \\
\hline \multicolumn{6}{|c|}{ a. Analytical gradient protocol (Waters and Varian systems) } \\
\hline 0 & 1.0 & 100 & 0 & 0 & Injection \\
\hline 4 & 1.0 & 0 & 100 & 0 & Linear gradient \\
\hline 18 & 1.0 & 0 & 20 & 80 & Linear gradient \\
\hline 21 & 1.0 & 0 & 100 & 0 & Linear gradient \\
\hline 24 & 1.0 & 100 & 0 & 0 & Linear gradient \\
\hline 29 & 1.0 & 100 & 0 & 0 & Equilibration \\
\hline \multicolumn{6}{|c|}{ b. Modified protocol on Spectraphysics systems } \\
\hline 0 & 1.0 & 100 & 0 & 0 & Injection \\
\hline 2 & 1.0 & 0 & 100 & 0 & Linear gradient \\
\hline 2.6 & 1.0 & 0 & 90 & 10 & Linear gradient \\
\hline 13.6 & 1.0 & 0 & 65 & 35 & Linear gradient \\
\hline 20 & 1.0 & 0 & 31 & 69 & Linear gradient \\
\hline 22 & 1.0 & 0 & 100 & 0 & Linear gradient \\
\hline 25 & 1.0 & 100 & 0 & 0 & Linear gradient \\
\hline 30 & 1.0 & 100 & 0 & 0 & Equilibration \\
\hline \multicolumn{6}{|c|}{ c. Shutdown protocol } \\
\hline 0 & 1.0 & 100 & 0 & 0 & Analysis complete \\
\hline 3 & 1.0 & 0 & 100 & 0 & Linear gradient \\
\hline 6 & 1.0 & 0 & 0 & 1.00 & Linear gradient \\
\hline 16 & 1.0 & 0 & 0 & 100 & Washing \\
\hline 17 & 0 & 0 & 0 & 100 & $\begin{array}{l}\text { Shut down; } \\
\text { linear gradient }\end{array}$ \\
\hline
\end{tabular}

Pigment identification. Pigments were identified by co-chromatography with authentic standards prepared for the SCOR Carotenoid Workshop (for details see SCOR report, in prep.), by diode array spectroscopy during elution, and by transferring HPLC fractions to standard solvents and comparing their visible absorption spectra with reference standards (Foppen 1971 . Davies 1976, Wright \& Shearer 1984, SCOR Carotenoid Workshop Report in prep.). A Shimadzu Model RPI recording spectrophotometer was used for UV-visible spectroscopy of purified pigments.

Preparation of additional standard pigments. Chlorophyll derivatives and carotenoids not found in the standard algal cultures were prepared separately. Chlorophyllides $a$ and $b$ were obtained from cultures of Phaeodactylum tricornutum (chlorophyllide a) and Dunaliella tertiolecta (chlorophyllides $a$ and $b$ ), by incubating harvested algae in $50 \%$ acetone in the dark to allow the endogenous chlorophyllase to hydrolyse the parent chlorophylls (Barrett \& Jeffrey 1964, 1971, Lorenzen \& Jeffrey 1980). Spectroscopically pure pigments were then obtained by HPLC.

Phaeophytins $a$ and $b$ and phaeophorbides $a$ and $b$ were prepared by acidification (1 $\mathrm{M} \mathrm{HCl}$ ) of acetone solutions of the corresponding chlorophylls and chlorophyllides respectively, which were then transferred to diethyl ether and washed against several changes of water to remove the acid (Lorenzen \& Jeffrey 1980).

$19^{\prime}$-Hexanoyloxy-and 19'-butanoyloxyfucoxanthin were obtained from cultures of Emiliania huxleyi and Pelagococcus subviridis respectively, and purified on Merck HPTLC RP-8 plates (Wright \& Jeffrey 1987).

Peridinin was prepared from Amphidinium carterae by chromatography of pigment extracts on Merck HPTLC RP-8 plates (1 dimension, solvent system methanol: water $=19: 1(\mathrm{v} / \mathrm{v}))$. Diadinochrome was obtained by acid-catalyzed rearrangement of diadinoxanthin ex Euglena gracilis. Siphonein and siphonaxanthin were isolated from the siphonous alga Codium fragile by HPTLC as described for peridinin above. Echinenone (synthetic) and lycopene (from tomatoes) were gifts from Hoffmann-La Roche, Basel, to Dr S. Liaaen-Jensen, Trondheim, Norway. Canthaxanthin was a synthetic standard provided by Dr D. Repeta. Ethyl 8'- $\beta$-apocarotenoate, purchased from Fluka Chemicals, USA, was suggested by Repeta as a possible quantitative internal standard and it was included in these tests to ensure that it did not co-chromatograph with known marker pigments. Another synthetic carotenoid, trans- $\beta$-apo-8'-carotenal, purchased from Sigma Chemical Co., was included as an internal standard in the field sample. All pigments were stored in the dark at $-20{ }^{\circ} \mathrm{C}$ or in liquid nitrogen until used. In our experience, if the solvent remains frozen the pigments are stable indefinitely, otherwise pigments degrade over a period of days to weeks.

Pigment recovery. Recovery of pigments was measured by comparing peak areas for peridinin, lutein, chlorophyll $b$, chlorophyll $a$, and $\beta, \beta$-carotene using the gradient and column described above with those obtained using isocratic buffered methanol (first phase of the gradient) and stainless steel tubing instead of the column (5 replicates). Figures were not corrected for differences in extinction coefficients in the different mobile phases.

\section{RESULTS}

Chromatograms of 12 unialgal pigment extracts taken from log phase cultures are shown in Fig. 1 Excellent resolution of almost all individual pigments was achieved for each species.

Fig. 2 shows the resolution of a comprehensive pigment mixture prepared by pooling extracts from 7 reference algae supplemented with additional carotenoid and chlorophyll derivatives; giving a suite of over 40 pigments. Thirty-nine pigments were resolved with 37 securely identified. Table 4 lists the pigments separated in increasing elution order, together with a summary of their UV-visible spectral characteristics. Full 
visible spectra in appropriate solvents (including HPLC eluant) are available in the SCOR Working Group 78 Carotenoid Report (in prep.).

At the polar end of the chromatogram, the phytolfree chlorophyll derivatives chlorophyllide $b$, chlorophyllide a (Fig. 1a) and chlorophyll $c_{3}$ (Fig. 1e) were almost completely resolved from chlorophyll $c_{1}+c_{2}+$ Mg2,4D which coeluted as a single peak (Figs. 1b \& 2).

In the complex central region of the chromatogram, most of the known carotenoid bio-markers (peridinin, fucoxanthin, prasinoxanthin, violaxanthin, alloxanthin, lutein, zeaxanthin, canthaxanthin and siphonein) were adequately resolved. Only 2 pairs of carotenoids were not separated: 19'-butanoyloxyfucoxanthin from siphonaxanthin, and $19^{\prime}$-hexanoyloxyfucoxanthin from $9^{\prime}$ cis-neoxanthin, although the individual components of each pair could be distinguished spectrally by diode array detection. Many minor carotenoid components were also resolved and identified (Figs. 1 \& 2 and Table 4).

At the non-polar end of the chromatogram, the phytolated chlorophylls $a$ and $b$, the phaeophytins, and the less-polar carotenoids and carotenes were resolved. In fresh extracts, the native chlorophylls predominated with a very small proportion of chlorophyll a allomer, epimer and trace unknown chlorophyll a derivatives (less than $1 \%$ ). We cannot determine whether such trace pigments are present in situ, or are formed during the short ( 1 to $10 \mathrm{~d}$ ) low temperature storage period or the short 'extraction to injection' period. The internal carotenoid standard, ethyl $8^{\prime}-\beta$-apocarotenoate, separated as a single peak between chlorophyll $b$ and chlorophyll a (Fig. 2). The other internal standard, trans- $\beta$-apo-8'-carotenal, co-chromatographed with canthaxanthin, eluting before chlorophyll $b$ (Fig. 3). The hydrocarbons, lycopene $(\psi, \psi$-carotene) and $\beta, \psi$ carotene, were completely resolved. $\beta, \varepsilon$-Carotene eluted as the leading shoulder of the $\beta, \beta$-carotene peak. Cis- $\beta$, $\beta$-carotene eluted as the trailing shoulder of the $\beta, \beta$-carotene peak (see Figs. $1 \mathrm{a} \& 2$ ).

Recovery of pigments from the column was excellent. Recoveries measured were: peridinin, $102 \%$; lutein, $107 \%$; chlorophyll b, $100 \%$; chlorophyll a, $107 \%$; and $\beta, \beta$-carotene, $98 \%$. Recovery figures greater than $100 \%$ may reflect the different extinction coefficients in the mobile phases used.

In each of the single algal chromatograms, the native all-trans carotenoids predominated, with only small amounts of cis-isomers. Note that in Dunaliella tertiolecta (Fig. 1a), and all other green algae to our knowledge, neoxanthin is present as the $9^{\prime}$-cis isomer in fresh extracts (Bjornland 1990). The trans isomer appears in the extract within hours of preparation.

Most of the pigments of the species examined have been characterised with modern spectrometric methods and require no detailed discussion here (cf. Table 1). Exceptions are those of Dunaliella tertiolecta (Fig. 1a), Porphyridium cruentum (Fig. 1l) and the widely-distributed prasinophyte Micromonas pusilla (Fig. 1h). The last species contains the chlorophyll clike pigment $\mathrm{Mg}$ 2,4D (Fookes \& Jeffrey unpubl.), and a range of carotenoids differing from those of normal chlorophytes (see Dunaliella tertiolecta, Fig. 1a), and prasinoxanthin-containing prasinophytes (Pycnococcus provasolii, Fig. 1g). Two significant carotenoid components in $M$. pusilla had siphonaxanthin-like spectra; the first one (peak 18) almost co-chromatographed with prasinoxanthin but differed from it spectrally in lacking any trace of a shoulder at about $475 \mathrm{~nm}$. It is possible that minor contaminants may be altering its apparent spectrum. In some cultures, a leading shoulder was observed on peak 18 , having maxima at (406), 429 and $455 \mathrm{~nm}$. A similar shoulder was observed on the neoxanthin peak with maxima at 447 and 470 $\mathrm{nm}$. The identity of these pigments is presently being studied by Dr S Liaaen-Jensen and co-workers, Trondheim, Norway.

Two phaeophorbide a-like peaks co-eluted with carotenoids but did not interfere with detection of the carotenoids because they did not absorb at $436 \mathrm{~nm}$. The phaeophorbides can be detected without interference from carotenoids using fluorescence (excitation $407 \mathrm{~nm}$, emission $672 \mathrm{~nm}$ for phaeophorbide $a_{\text {; excita- }}$ tion 432 and emission $659 \mathrm{~nm}$ for phaeophorbide b); or absorption at 405 or $665 \mathrm{~nm}$

Fig. 3 shows the resolution of chlorophylls and carotenoids from a field sample from the Southern Ocean in the vicinity of Heard Island. Note that the field sample was analysed with the Spectraphysics HPLC system and the retention times do not exactly match those of the Varian HPLC system, listed in Table 4. The absence of chlorophyll a epimer and chlorophyllides indicated that little degradation had occurred. The chromatogram shows a good resolution of the major pigments. Apart from chlorophyll $a$, the chromatogram is dominated by fucoxanthin, its 19'hexanoyloxy- and 19'-butanoyloxy-derivatives, chlorophylls $c_{3}$ and $c_{1}+c_{2}$, and diadinoxanthin. Smaller amounts of peridinin, chlorophyll $b$, prasinoxanthin, and antheraxanthin were present along with traces of alloxanthin and zeaxanthin.

Examination of the samples by light microscopy showed them to be dominated by small diatoms (consistent with the abundance of fucoxanthin), a numerically smaller dinoflagellate population (indicated by peridinin) with many unidentifiable flagellates. The pigment composition suggests that the flagellates comprised mainly prymnesiophytes (chlorophyll $c_{3}$, fucoxanthin, $19^{\prime}$-hexanoyloxyfucoxanthin and $19^{\prime}$-butanoyloxyfucoxanthin) together with smaller populations 


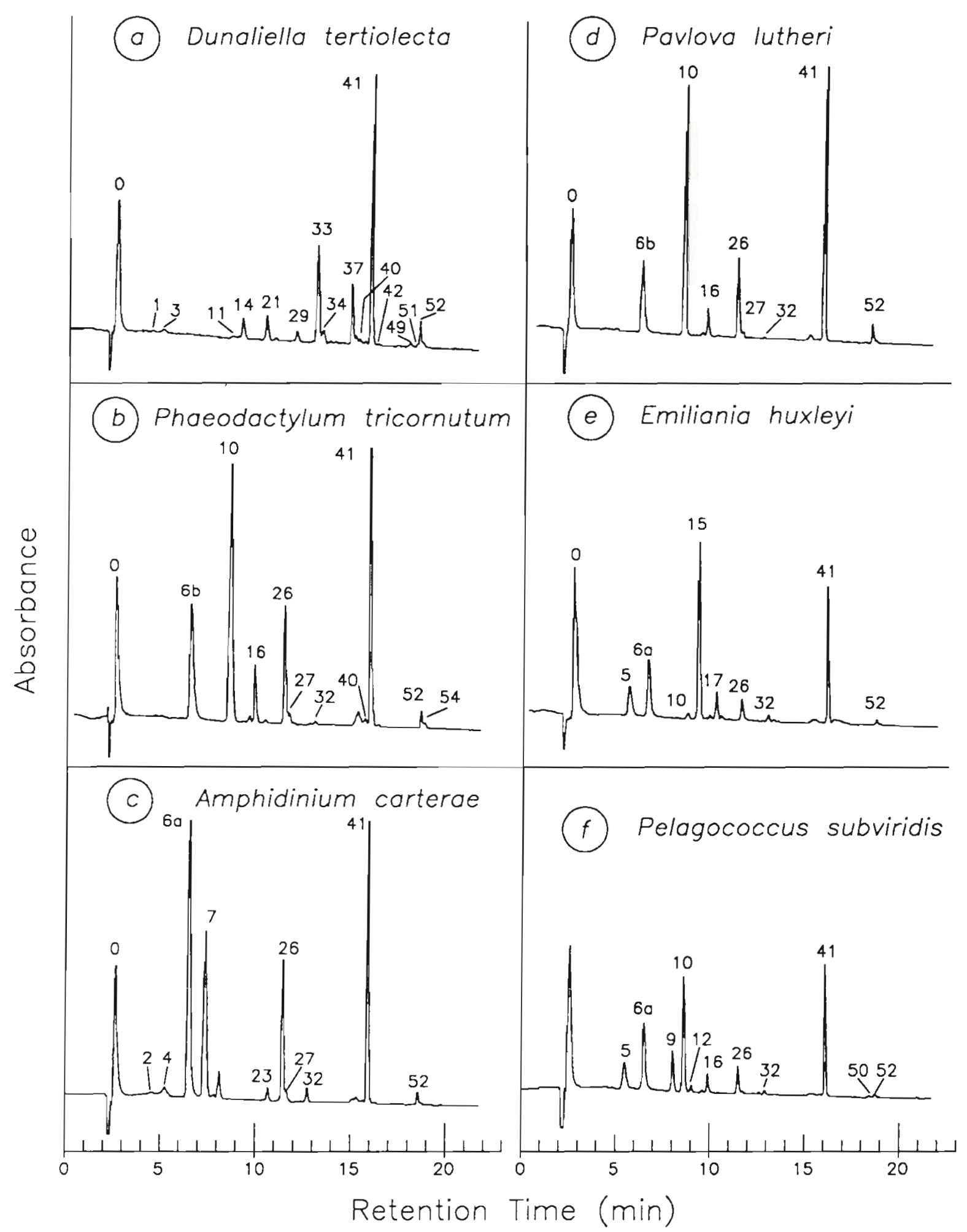




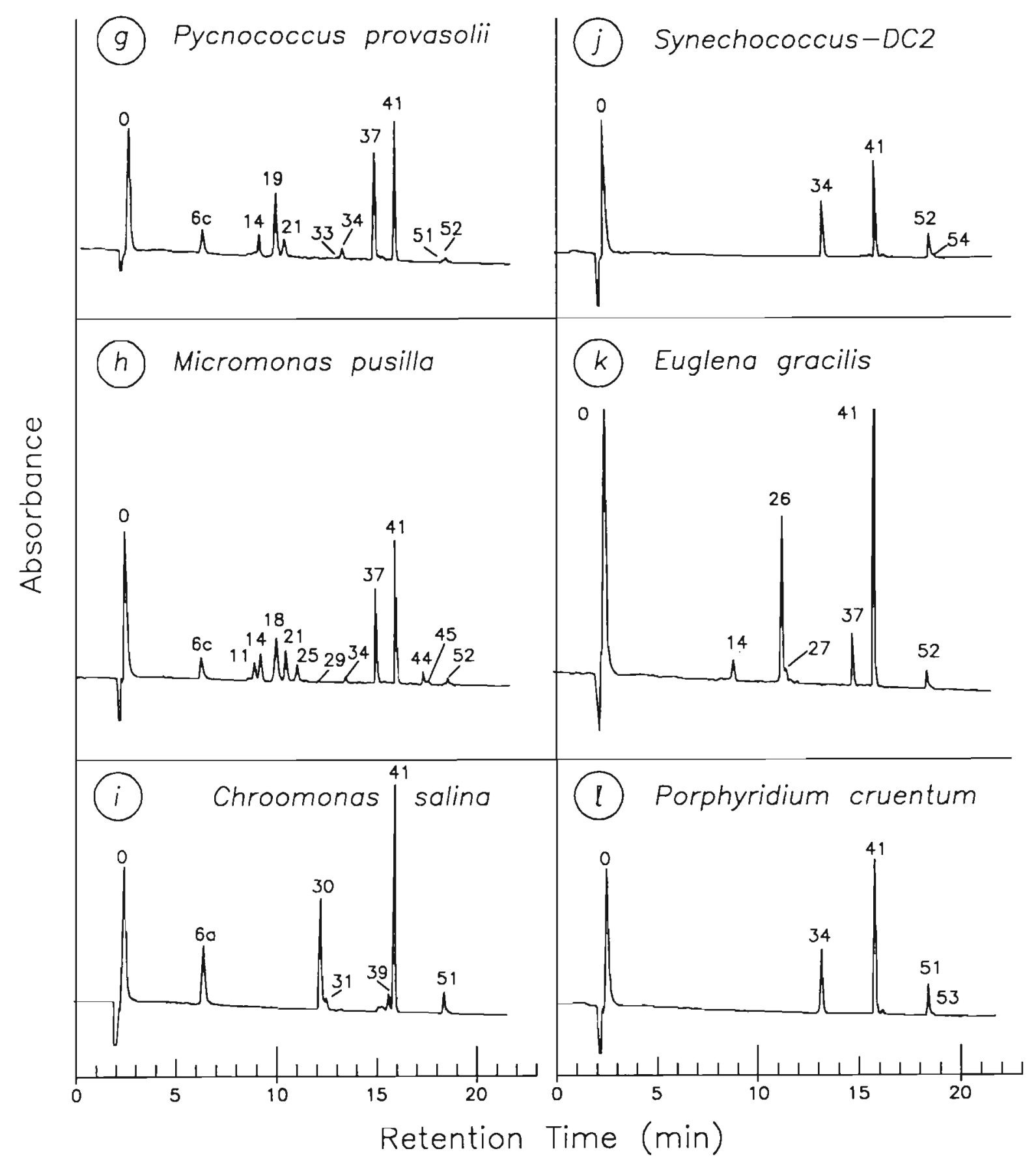

Fig. 1. HPLC traces of pigment separations of unialgal cultures of 12 reference microalgae: (a) Dunaliella tertiolecta (green alga); (b) Phaeodactylum tricornutum (diatom); (c) Amphidinium carterae (dinoflagellate); (d) Pavlova lutheri (prymnesiophyte); (e) Emiliania huxleyi (prymnesiophyte); (f) Pelagococcus subviridis (chrysophyte); (g) Pycnococcus provasolii (prasinophyte); (h) Micromonas pusilla (prasinophyte); (i) Chroomonas salina (cryptomonad); (j) Synechococcus sp. (cyanophyte); (k) Euglena gracilis (euglenoid); and (l) Porphyridium cruentum (red alga). For identity of pigment fractions see Table 4 . Chromatograms obtained with the Varian system 


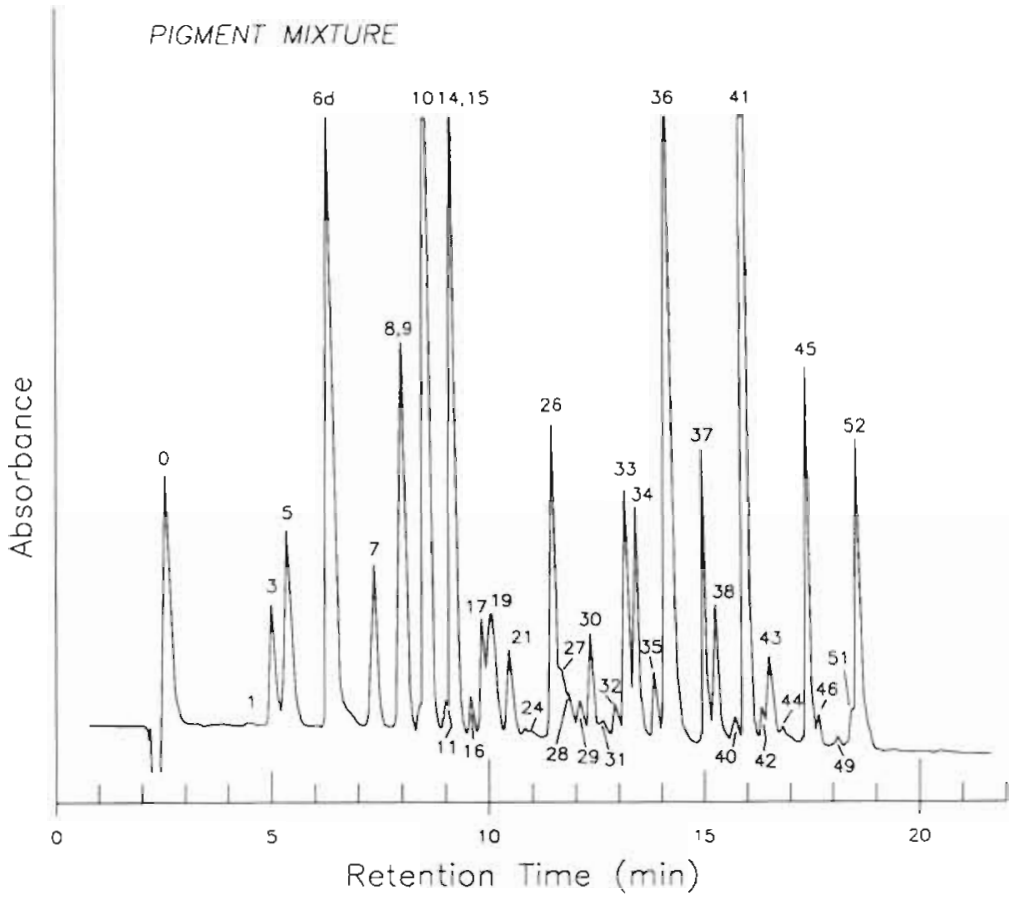

Fig. 2. HPLC traces of a mixed pigment extract from algal cultures of Dunaliella tertiolecta (green alga), Phaeodactylum tricornutum (diatom), Synechococcus sp. (cyanophyte), Pycnococcus provasolii (prasinophyte), Chroomonas salina (cryptomonad), Emiliania huxleyi (prymnesiophyte), Pelagococcus subviridis (chrysophyte), and the authentic carotenoids diadinochrome, siphonein, siphonaxanthin, echinenone, canthaxanthin, lycopene, peridinin and the internal synthetic standard ethyl 8'- $\beta$-apocarotenoate. For identity of pigment fractions see Table 4. Chromatogram obtained with the Varian system

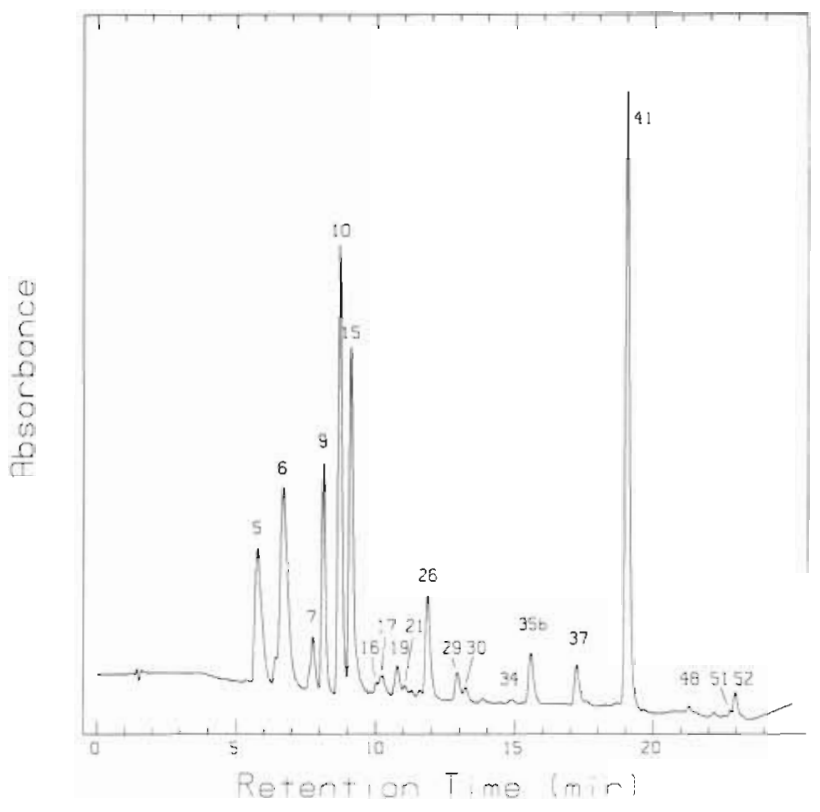

Fig. 3. HPLC trace of phytoplankton sample from the Southern Ocean $\left(51^{\circ} 54^{\prime} \mathrm{S}, 73^{\circ} 14^{\prime}\right.$ E, 9 June 1990$)$. For identity of pigment fractions see Table 4 . Chromatogram obtained with the Spectraphysics system

of prasinophytes (chlorophyll b, prasinoxanthin and antheraxanthin) and cryptomonads (alloxanthin).

\section{DISCUSSION}

In the development of this HPLC method, 12 species from 10 algal classes were examined (Table 1). While this range is comprehensive, one algal class with representatives widely distributed in the tropical ocean but not included here is the Prochlorophyceae. No culture of an isolated representative was available at the time of the workshop. Prochlorophytes contain a chlorophyll a-like pigment instead of chlorophyll a (Chisholm et al. 1988, Veldhuis \& Kraay 1990), now identified as 8-desethyl, 8-vinyl chlorophyll a (Goericke \& Repeta in press). These 2 pigments can be separated in normal phase HPLC systems (Gieskes \& Kraay 1983a), but coelute in reverse phase systems unless converted to their respective pheophytins, a technique subject to interference by an unknown carotenoid, according to an anonymous reviewer.

The present method has a number of advantages over other published methods for phytoplankton pigments (Roy 1987), in that separation of over 50 key carotenoids, chlorophylls and chlorophyll derivatives is achieved in one simple ternary gradient system.

In comparison with the technique of Wright \& Shearer (1984) the resolution of polar chlorophylls and carotenoids has been enhanced, while retaining the resolution of later-eluting pigments. Of particular importance is the pigment pair lutein and zeaxanthin, not separated by Mantoura \& Llewellyn (1983) or Gieskes \& Kraay (1986b). The new method retains the almost baseline resolution for this pigment pair of Wright \& Shearer (see Fig. 2), similar to that of BenAmotz et al. (1982), although it does not match the excellent separation achieved by Zapata et al. (1987). However, Zapata's resolution of other carotenoids is inferior to our improved method, as shown by compar- 
Table 4. Elution order of pigments from standard cultures and their visible absorption characteristics

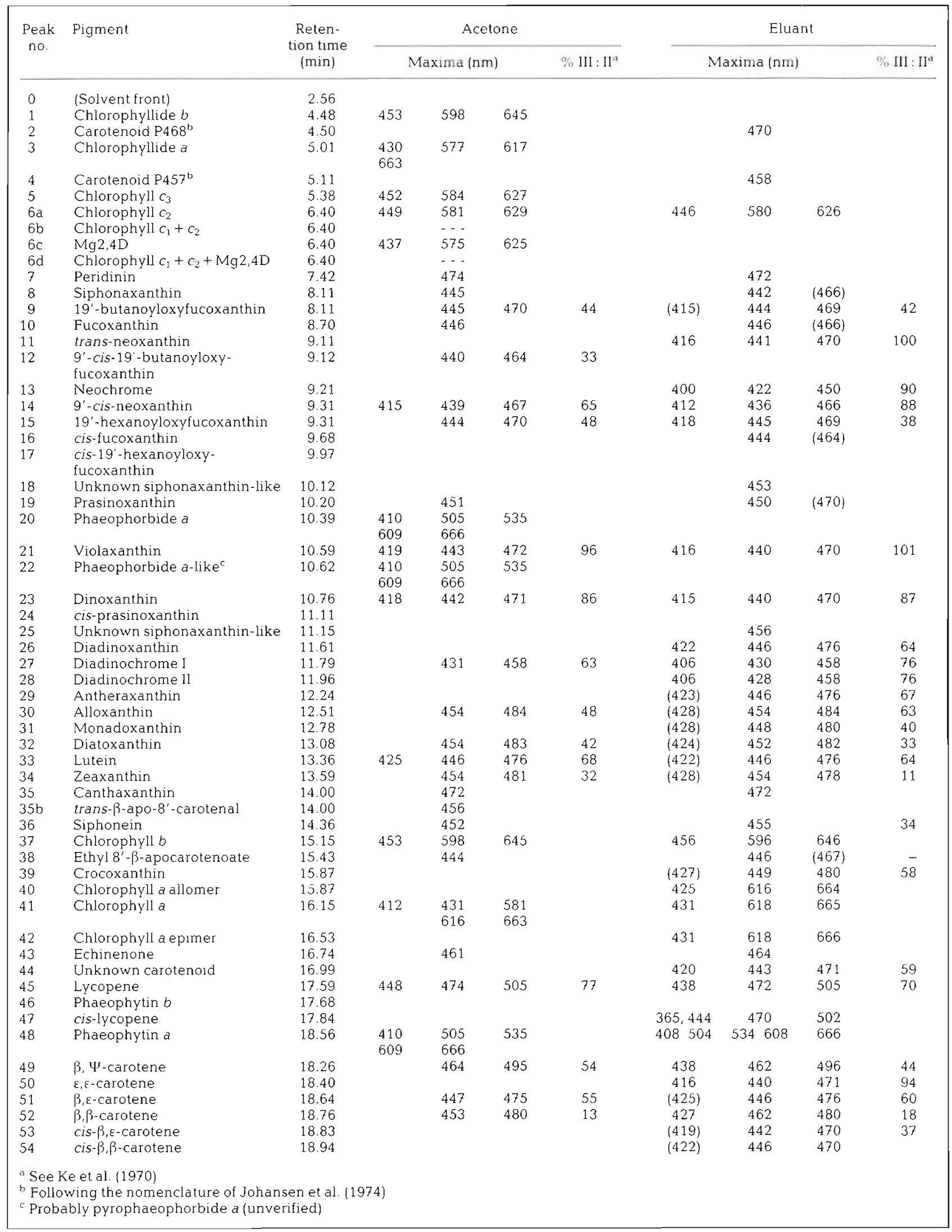


Table 5. Summary of major signature pigments for algal types and processes in the ocean

\begin{tabular}{|c|c|c|}
\hline Pigment & Algal type or process & Source \\
\hline Chlorophyll a & All photosynthetic microalgae, except prochlorophytes & 1 \\
\hline 8-desethyl, 8-vinyl chlorophyll a & Prochlorophytes & 2,3 \\
\hline Chlorophyll $b$ & Chlorophytes, prasinophytes, euglenophytes, prochlorophytes & 1,2 \\
\hline Chlorophyll c family & Chromophyte algae & 4 \\
\hline$c_{1}$ & Most diatoms, some prymnesiophytes, some chrysophytes & $4,5,6$ \\
\hline$c_{2}$ & Most marine chromophyte algae (except some chrysophytes) & $4,5,6$ \\
\hline$c_{3}$ & Some prymnesiophytes, chrysophytes, diatoms & $4,7,8$ \\
\hline $\begin{array}{l}\text { Mg 2,4-divinylpheoporphyrin } a_{5} \\
\text { monomethyl ester }(\mathrm{Mg} 2,4 \mathrm{D})\end{array}$ & Some prasinophytes & 9,10 \\
\hline Fucoxanthin & $\begin{array}{l}\text { Diatoms, prymnesiophytes, chrysophytes, raphidophytes, a few } \\
\text { dinoflagellates }\end{array}$ & 1,11 \\
\hline $\left.\begin{array}{l}19^{\prime} \text {-hexanoyloxyfucoxanthin } \\
19^{\prime} \text {-butanoyloxyfucoxanthin }\end{array}\right\}$ & Some chrysophytes, prymnesiophytes, 1 diatom, a few dinoflagellates & $8,11,12,13$ \\
\hline Peridinin & Most photosynthetic dinoflagellates & 14,15 \\
\hline Zeaxanthin & Cyanobacteria (blue-green algae), prochlorophytes, green-algae & 16,17 \\
\hline Fucoxanthin and violaxanthin & Some chrysophytes & 11,18 \\
\hline Alloxanthin & Cryptomonads & 19 \\
\hline Prasinoxanthin & Some prasinophytes & 20 \\
\hline Lutein & Green algae (chlorophytes and some prasinophytes) & 1 \\
\hline $\left.\begin{array}{l}\text { Phaeophytin a } \\
\text { Phaeophorbide } a\end{array}\right\}$ & Grazed phytoplankton; fecal pellets, sediments & 1,21 \\
\hline Chlorophyllide a & Extraction artefact, chlorophyllase-containing species & 22 \\
\hline Unidentified chl a derivatives & Senescent microalgae & 23 \\
\hline $\left.\begin{array}{l}\text { Pyrophaeophorbide } a \\
\text { Mesophaeophorbide a }\end{array}\right\}$ & Sediments & 24 \\
\hline \multicolumn{3}{|c|}{$\begin{array}{l}\text { Sources: } \\
\text { 1, Jeffrey (1974); 2, Chisholm et al. (1988); 3, Goericke \& Repeta (in press); 4, Jeffrey (1989); 5, Stauber \& Jeffrey (1988); } \\
\text { 6. Andersen \& Mulkey (1983); 7, Jeffrey \& Wright (1987); 8, Vesk \& Jeffrey (1987); 9, Ricketts (1966a); 10, Fookes \& Jeffrey } \\
\text { (unpubl.); 11, Bjornland \& Liaaen-Jensen (1989); 12, Wright \& Jeffrey (1987); 13, Bjornland et al. (1989); 14, Jeffrey et al. } \\
\text { (1975); 15, Johansen et al. (1974); 16, Guillard et al. (1985); 17, Gieskes et al. (1988); 18, Withers et al. (1981); 19; Pennington et } \\
\text { al. (1985); 20, Foss et al. (1984); 21, Vernet \& Lorenzen (1987); 22, Jeffrey \& Hallegraeff (1987); 23, Hallegraeff \& Jeffrey (1985); } \\
\text { 24, Mantoura (unpubl.) }\end{array}$} \\
\hline
\end{tabular}

ing the resolution of Dunaliella tertiolecta pigments (their Fig. 4B, and our Fig. 1a).

Further advantages of the method are that no ion pairing reagent is necessary as in the method of Mantoura \& Llewellyn (1983) and Bidigare et al. (1985), and no expensive radial compression module is used as in the original method of Wright \& Shearer (1984). Further, our early method trials, using 2 different liquid chromatographs (a Waters system and a Varian system), showed only slightly different retention times between the 2 instruments. Some differences in retention times but not retention sequence occurred in the Spectraphysics system (Fig. 3) which had a different dead volume between the pump and column.

Apart from the 39 pigments resolved in Fig. 2, 2 important fucoxanthin derivatives, 19'-hexanoyloxyfucoxanthin and $19^{\prime}$-butanoyloxyfucoxanthin, were not chromatographically separated from $9^{\prime}$-cis neoxanthin and siphonaxanthin respectively. Both 19'-acyloxyfucoxanthins are important indicators of particular prymnesiophytes, chrysophytes and dinoflagellates (see Table 5). The use of a diode array detector allows the pigments to be resolved spectroscopically, if not chromatographically, and this would seem an essential adjunct to pigment identification of field samples. To our knowledge, these pigment pairs have not been resolved in other reverse-phase HPLC systems.

While chlorophyll $c_{3}$ was clearly resolved from other chlorophyll $c$ pigments, the important chlorophylls $c_{1}$, $c_{2}$ and the chiorophyll $c$-like prasinophyte pigment $\mathrm{Mg}$ 2,4D could not be resolved from each other, similar to other HPLC systems using octadecylsilica columns (Mantoura \& Llewellyn 1983, Bidigare et al. 1985, Zapata et al. 1987. Gieskes \& Kraay 1988). The only known HPLC method capable of resolving these 4 chlorophyll $c$ pigments is that of Jeffrey \& Brown (unpubl.; described in Jeffrey 1989), which uses a special polyethylene column. It could be used in conjunction with the present method to obtain more detail on the chlorophyll $c$ pigments present. Confirmation that the prasinophyte chlorophyll c-like pigment is $\mathrm{Mg} 2,4 \mathrm{D}$ and not chlorophyll $c_{1}$ as was suggested by Wilhelm 
(1987) has come from spectral and chemical data (Jeffrey 1989, Fookes \& Jeffrey unpubl.). Indeed, a fifth chlorophyll c-like pigment was recently characterised from a prasinophyte (Jeffrey 1989, Fookes \& Jeffrey unpubl.).

Our improved method presented here fulfils an objective of SCOR Working Group 78 to recommend an HPLC method for resolution of phytoplankton chlorophylls and carotenoids in seawater and cultures of algae. Due to the complexity of pigment composition in field samples, caution should be exercised in the identification of pigments. Retention times, spectral analysis, chemical properties, and co-chromatography with known standards from reference cultures should all be included to confirm identifications, wherever possible.

Using HPLC techniques, important pigments characteristic of algal classes, groups of species or processes occurring in phytoplankton populations (Table 5) can be determined, but for quantitative assessment of the biomass of taxonomic groups the variability of pigment ratios must be taken into account mathematically (Gieskes \& Kraay 1983b, Gieskes et al. 1988). If definitive taxonomic characterization of individual species is required, HPLC should be complemented by other techniques such as light and electron microscopy of non-destructively preserved samples.

Acknowledgements. We thank the Scientific Committee for Oceanic Research (SCOR) for setting up Working Group 78: Measurement of Photosynthetic Pigments in Seawater, and supporting 'hands-on' workshops for pigment calibration studies. The advances reported in this paper would not have occurred without both the initiative and financial support of SCOR and UNESCO. T.B. was supported by a grant from the Norwegian Fisheries Research Council. We also thank Dr M. Brown for running pigment samples on the Varian HPLC, Dr S. Blackburn for assistance with algal cultures, Prof. S. LiaaenJensen for gifts of carotenoid standards, and Mr J. Cox for preparing the figures.

\section{LITERATURE CITED}

Andersen, R. A., Mulkey, T J. (1983). The occurrence of chlorophylls $c_{1}$ and $c_{2}$ in the Chrysophyceae. J. Phycol. 19: 289-294

Arpin, N., Svec, W A., Liaaen-Jensen, S. (1976). New fucoxanthin-related carotenoids from Coccolithus huxleyi. Phytochem. 15: 529-532

Barrett, J., Jeffrey, S. W. (1964). Chlorophyllase and formation of an atypical chlorophyllide in marine algae. Plant Physiol. 39: 44-47

Barrett, J., Jeffrey, S. W. (1971). A note on the occurrence of chlorophyllase in marine algae. J. exp. mar. Biol Ecol. 7: $255-262$

Ben-Amotz, A. Katz, A., Avron, M. (1982). Accumulation of $\beta$ carotene in halotolerant algae: purification and characterisation of $\beta$-carotene-rich globules from Dunaliella bardawil (Chlorophyceae). J. Phycol. 18: 529-537
Berger, R., Liaaen-Jensen, S., McAlister, V., Guillard, R. R. L. (1977). Carotenoids of the Prymnesiophyceae (Haptophyceae). Biochem. Syst. Ecol. 5: 71-75

Bidigare, R. R., Kennicutt, M. C., Brookes, J. M. (1985). Rapid determination of chlorophylls and their degradation products by high performance liquid chromatography. Limnol. Oceanogr. 30: 432-435

Bjornland, T (1989). Carotenoid structures and lower plant phylogeny. In: Krinsky, N. I., Mathews-Roth, M. M. Taylor, R. F. (eds.) Carotenoids: chemistry and biology Plenum Press, New York, p. 21-37

Bjornland, T., Liaaen-Jensen, S. (1989). Distribution patterns of carotenoids in relation to chromophyte phylogeny and systematics. In: Green, J. C., Leadbeater, B. S. C., Diver, $W$ L. (eds.) The chromophyte algae: problems and perspectives. Clarendon Press, Oxford, p. 37-60

Bjornland, T., Liaaen-Jensen, S., Throndsen, J. (1989). Carotenoids of the marine chrysophyte Pelagococcus subviridis. Phytochem. 28: 3347-3353

Chisholm, S. W., Olson, R. J., Zettler, E. R., Goericke, R., Waterbury, J. B., Welschmeyer, N. A. (1988). A novel, freeliving prochlorophyte abundant in the oceanic euphotic zone. Nature, Lond. 334: 340-343

Davies, B. H. (1976). Carotenoids. In: Goodwin, T W. (ed.) Chemistry and biochemistry of plant pigments, Vol. 2. Academic Press, London, p. 38-165

Fookes, C. J. R., Jeffrey, S. W. (1989). The structure of chlorophyll $c_{3}$, a novel marine photosynthetic pigment. J. chem. Soc. chem. Commun. 23: 1827-1828

Foppen, F. H. (1971). Tables for the identification of carotenoid pigments. Chromatog. Rev. 14: 133-298

Foss, P., Guillard, R. R. L., Liaaen-Jensen, S. (1984). Prasinoxanthin - a chemosystematic marker for algae. Phytochem. 23: 1629-1633

Gieskes, W. W. C., Kraay, G. W. (1983a). Unknown chlorophyll a derivatives in the North Sea and the tropical Atlantic Ocean revealed by HPLC analysis. Limnol. Oceanogr. 28: $757-766$

Gieskes, W. W. C., Kraay, G. W. (1983b). Dominance of Cryptophyceae during the phytoplankton spring bloom in the central North Sea detected by HPLC analysis of pigments. Mar. Biol. 75: 179-185

Gieskes, W. W C., Kraay, G. W. (1986a). Analysis of phytoplankton pigments by HPLC before, during and after mass occurrence of the microflagellate Corymbellus aureus during the spring bloom in the open northern North Sea in 1983. Mar Biol 92: 45-52

Gieskes, W. W C., Kraay, G. W. (1986b). Floristic and physiological differences between the shallow and the deep nanophytoplankton community in the euphotic zone of the open tropical Atlantic revealed by HPLC analysis of pigments. Mar Biol. 91: 567-576

Gieskes, W. W. C., Kraay, G. W., Nontji, A., Setiapermana, D., Sutomo (1988). Monsoonal alternation of a mixed and a layered structure in the phytoplankton of the euphotic zone of the Banda Sea (Indonesia): a mathematical analysis of algal pigment fingerprints. Neth. J. Sea Res. 22: 123-137

Goericke, R., Repeta, D. J. (in press). The pigments of Prochlorococcus minutus: the presence of chlorophyll $a_{1}$ and $b_{1}$ in a marine procaryote. Limnol. Oceanogr.

Guillard, R. R. L., Ryther, J. H. (1962). Studies of marine plankton diatoms. I. Cyclotella nana Hustedt and Detonula confervacea (Cleve) Gran. Can. J. Microbiol. 8: 229-239

Guillard, R. R. L., Keller, M. D., O'Kelly, C. J., Floyd, G. L. (1991). Pycnococcus provasolii gen. et $\mathrm{sp}$. nov, a coccoid prasinoxanthin-containing phytoplankter from the Western North Atlantic and Gulf of Mexico. J. Phycol. 27: 39-47 
Guillard, R. R. L., Murphy, L. S., Foss, P., Liaaen-Jensen, S. (1985). Synechococcus spp. as likely zeaxanthin-dominant ultraphytoplankton in the North Atlantic. Limnol. Oceanogr 30: 412-414

Hallegraeff, G. M., Jeffrey, S. W. (1985). Description of new chlorophyll a alteration products in marine phytoplankton. Deep Sea Res, 32: 697-705

Holm-Hansen, O., Lorenzen, C. J., Holmes, R. W., Strickland, J. D. H. (1965). Fluorimetric determination of chlorophyll. J. Cons. perm. int. Explor. Mer 30:3-15

Hooks, C. E., Bidigare, R. R., Keller, M. D., Guillard, R. R. L. (1988). Coccoid eukaryotic marine ultraplankters with four different HPLC pigment signatures. J. Phycol. 24: $571-580$

Jeffrey, S. W. (1968). Quantitative thin-layer chromatography of chlorophylls and carotenoids from marine algae. Biochim. biophys. Acta 162: 271-285

Jeffrey, S. W. (1974). Profiles of photosynthetic pigments in the ocean using thin-layer chromatography. Mar. Biol. 26: $101-110$

Jeffrey, S. W (1980). Cultivating unicellular marine plants CSIRO (Hobart, Tasmania) Fish and Oceanogr Ann. Rep. $1977-1979$, p. $22-43$

Jeffrey, S. W. (1981). An improved thin-layer chromatographic technique for marine phytoplankton pigments. Limnol. Oceanogr 26: 191-197

Jeffrey, S. W. (1989). Chlorophyll $c$ pigments and their distribution in the chromophyte algae. In: Green, J. C., Leadbeater, B. S. C., Diver, W L. (eds.) The chromophyte algae: problems and perspectives. Clarendon Press, Oxford, p. 13-36

Jeffrey, S. W., Hallegraeff, G. M. (1987). Chlorophy]lase distribution in 10 classes of phytoplankton - a problem for chlorophyll analysis. Mar. Ecol. Prog. Ser. 35: 293-304

Jeffrey, S. W., Humphrey, G. F. (1975). New spectrophotometric equations for determining chlorophylls $a_{1} b_{1} c_{1}$ and $c_{2}$ in higher plants, algae and natural phytoplankton. Biochern. Physiol. Pflanz. 167: 191-194

Jeffrey, S. W., Sielicki, M., Haxo, F. T (1975). Chloroplast pigment patterns in dinoflagellates. J. Phycol. 11: 374-384

Jeffrey, S. W., Wright, S. W. (1987). A new spectrally distinct component in preparations of chlorophyll $c$ from the microalga Emiliania huxleyi (Prymnesiophyceae). Biochim. biophys. Acta 894: 180-188

Johansen, J. E., Svec, W A., Liaaen-Jensen, S., Haxo, F. T (1974). Carotenoids of the Dinophyceae. Phytochem. 13 2261-2271

Ke, B., Imsgard, F., Kjøsen, H., Liaaen-Jensen, S. (1970) Electronic spectra of carotenoids at $77^{\circ} \mathrm{K}$. Biochim. biophys. Acta 210: 139-152

Loeblich, A. R., Smith, V E. (1968). Chloroplast pigments of the marine dinoflagellate Gyrodinium resplendens. Lipids 3: $5-13$

Lorenzen, C. J. (1967). Determination of chlorophyll and pheopigments: spectrophotometric equations. Limnol. Oceanogr 12: 343-346

Lorenzen, C. J., Jeffrey, S. W (1980). Determination of chlorophyll in seawater. UNESCO Tech. Pap. Mar. Sci. 35 p. $1-20$

Mantoura, R. F. C.. Llewellyn, C. A. (1983). The rapid determi nation of algal chlorophyll and carotenoid pigments and their breakdown products in natural waters by reversephase high-performance liquid chromatography. Analyt. Chim. Acta 151: 297-314

Nichols, H. W (1973). Growth media-freshwater In: Stein
J. R. (ed.) Handbook of phycological methods. Cambridge University Press, Cambridge, p. 7-24

Pennington, F., Guillard, R. R. L., Liaaen-Jensen, S. (1988) Carotenoid distribution patterns in the Bacillariophyceae Biochem. Syst. Ecol. 16: 589-592

Pennington, F. C., Haxo, F. T., Borch, G., Liaaen-Jensen, S (1985). Carotenoids of Cryptophyceae. Biochem. Syst Ecol. 13: 215-219

Repeta, D. J., Gagosian, R. B. (1982). Carotenoid transformations in coastal marine waters. Nature, Lond. 295: 51-54

Ricketts, I R. (1966a). Magnesium 2,4-divinylpheoporphyrin a $_{5}$ monomethyl ester, a protochlorophyll-like pigment present in some unicellular flagellates. Phytochem. 5: 223-229

Ricketts, T R. (1966b). The carotenoids of the phytoflagellate. Micromonas pusilla. Phytochem. 5: 571-580

Ricketts, T. R. (1970). The pigments of the Prasinophyceae and related organisms. Phytochem. 9: 1835-1842

Roy, S. (1987). High performance liquid chromatographic analysis of chloropigments. J. Chromatog. 391. 19-34

Stauber, J. L., Jeffrey, S. W (1988). Photosynthetic pigments in 51 species of marine diatoms. J. Phycol. 24: 158-172

Stransky, H., Hager, A. (1970). Das Carotinoidmuster und die Verbreitung des lichtinduzierten Xanthophyllcyclus in verschiedenen Algenklassen. IV. Cyanophyceae und Rhodophyceae. Arch. Mikrobiol. 72: 84-96

Strickland, J. D. H., Parsons, T R. (1972). A practical handbook of seawater analysis, 2nd edn. Bull. Fish. Res. Bd Can. 167

Strom, S. L., Welschmeyer, N. A. (1991). Pigment-specific rates of phytoplankton growth and microzooplankton grazing in the open subarctic Pacific Ocean. Limnol. Oceanogr. 36: 50-63

Veldhuis, M. J. W., Kraay, G. W. (1990). Vertical distribution and pigment composition of a picoplanktonic prochlorophyte in the subtropical North Atlantic: a combined study of HPLC analysis and flow cytometry. Mar. Ecol. Prog. Ser. 68: $121-127$

Vernet, M., Lorenzen, C. J. (1987). The presence of chlorophyll $b$ and the estimation of phaeopigments in marine phytoplankton. J. Plankton Res. 9: 255-265

Vesk, M., Jeffrey, S. W. (1987). Ultrastructure and pigments of two strains of the picoplanktonic alga, Pelagococcus subviridis (Chrysophyceae). J. Phycol. 23: 322-336

Welschmeyer, N. A., Hoepffner, N. (in press). Xanthophyll cycling I. Dynamics of rapid, light-induced pigment changes in phytoplankton. Limnol. Oceanogr

Wilhelm, C. (1987). Purification and identification of chlorophyll $c_{1}$ from the green alga Mantoniella squamata. Biochem. biophys. Acta 892: 23-29

Withers, N. W., Fiksdahl, A., Tuttle, R. C., Liaaen-Jensen, S (1981). Carotenoids of the Chrysophyceae. Comp. Biochem. Physiol. 68B: 345-349

Wright, S. W., Jeffrey, S. W. (1987). Fucoxanthin pigment markers of marine phytoplankton analysed by HPLC and HPTLC. Mar Ecol. Prog. Ser. 38: 259-266

Wright, S. W. Shearer, J. D. (1984). Rapid extraction and highperformance liquid chromatography of chlorophylls and carotenoids from marine phytoplankton. J. Chromatog. 294: 281-295

Zapata, M., Ayala, A. M., Franco, J. M., Garrido, J. L. (1987). Separation of chlorophylls and their degradation products in marine phytoplankton by reversed-phase high performance liquid chromatography. Chromatographia 23: $26-30$ 